\title{
COLETIVIZAÇÃO DO CONTROLE JUDICIAL DE POLÍTICAS PÚBLICAS: CONCRETIZAÇÃO IGUALITÁRIA E RACIONAL DE DIREITOS SOCIAIS
}

\section{CLASS ACTIONS TO JUDICIAL REVIEW OF PUBLIC POLICIES: EGALITARIAN AND RATIONAL IMPLEMENTATION OF SOCIAL-ECONOMIC RIGHTS}

\author{
Marcos Nassar* \\ Lídia Maria Ribas**
}

\begin{abstract}
RESUMO: O texto, que é um resultado da análise bibliográfica, jurisprudencial e dos números disponíveis, intenta demonstrar a necessidade de coletivização do controle judicial das políticas públicas relacionadas a direitos sociais, para viabilizar a aferição da reserva do possível à luz do princípio da igualdade (possibilidade de universalização do direito), com a prolação de decisões erga omnes, e ante outras características do processo coletivo: ampliação da discussão democrática por meio de audiências públicas e intervenção de amicus curiae, possibilidade de reflexão mais profunda e embasada sobre temas complexos, notadamente quanto à forma de execução da decisão e suas consequências.
\end{abstract}

Palavras-chave: Judicialização. Direitos sociais. Igualdade. Complexidade. Tutela coletiva.

ABSTRACT: From the bibliographical analysis, case law and available numbers, the study aims to demonstrate the need of class actions to judicial review of public policies related to social-economic rights, in order to enable the assessment of the public budget scarcity, with particular regard to the principle of equality (possibility of provision's universalization). Besides, class actions allow a broadening of the democratic discussion through public hearings and "amicus curiae" intervention and the possibility of a more profound and reasoned reflection on complex issues, including the decision's execution and its consequences.

Keywords: Judicial review. Social-economic rights. Equality. Complexity. Class actions.

\footnotetext{
* Mestrando em Direitos Humanos na UFMS. Procurador da República e Procurador Regional Eleitoral em Mato Grosso do Sul.

** Doutora e Mestre em Direito do Estado pela PUC/SP. Pesquisadora e professora permanente do Mestrado em Direitos Humanos da UFMS. Coordenadora do Grupo de Pesquisas no CNPq - Direito, Políticas Públicas e Desenvolvimento Sustentável. Membro do CEDIS/UNL.
} 


\section{INTRODUÇÃO}

Constitui o objeto deste artigo a análise das vantagens ou até necessidade de coletivização do controle judicial das políticas públicas relativas a direitos fundamentais sociais - em sentido amplo, abarcando os econômicos, sociais e culturais - como o direito à saúde, por exemplo.

Para tanto abordar-se-ão, entre outras questões: ( $I$ ) a possibilidade de tal controle judicial; (ii) a reserva do possível, em suas dimensões fática e jurídica, à luz do princípio da igualdade (possibilidade de universalização do direito social discutido) e da imposição constitucional de que as prioridades orçamentárias sejam orientadas pelo mínimo existencial, com um aporte, ainda, acerca da corrupção; (iii) a diferença entre a exigência de prestação definida no ordenamento jurídico e verdadeiro controle da política pública ou de sua inexistência; (iv) as diversas críticas dirigidas ao controle judicial das políticas públicas, em sua maioria referentes à litigância individual repetitiva; e $(v)$ o exame das características do processo coletivo que o tornam adequado à realização do aludido controle - inclusive sob a perspectiva do interesse processual -, em face, notadamente, do princípio da igualdade, da ampliação da discussão democrática por meio de audiências públicas e intervenção de amici curiae e da possibilidade de reflexão mais profunda e embasada sobre temas complexos, em especial quanto à forma de execução da decisão e suas consequências.

O estudo parte da revisão bibliográfica dos principais textos acerca do objeto estudado, da jurisprudência a respeito dos tribunais de superposição, bem como dos dados e números disponíveis acerca da judicialização do direito à saúde.

O momento afigura-se oportuno para a revisitação do tema, porquanto, afora merecer reflexão e enfrentamento a enorme quantidade de demandas sobre a efetivação de importantes direitos sociais enfrentada pelo Judiciário - máxime sobre saúde -, ganhou tramitação recentemente, na Câmara dos Deputados, Projeto de Lei para disciplinar o controle judicial de políticas públicas, como se noticiará. 


\section{JUdICIALIZAÇÃO DE POLÍtICAS PÚBLICAS VOLTADAS CONCRETIZAÇÃO DE DIREITOS FUNDAMENTAIS SOCIAIS}

A judicialização de políticas públicas é fenômeno há muito conhecido no Brasil e inerente à atual ordem constitucional, garantidora de inúmeros direitos fundamentais sociais. ${ }^{1}$

A possibilidade, em tese, dessa judicialização não demanda mais grandes discussões; é hoje algo assentado em nosso sistema. As discussões concentram-se agora na forma e nos limites do controle judicial.

Com efeito, há algum tempo está sedimentado na jurisprudência, inclusive no Supremo Tribunal Federal², que é permitido ao sistema de Justiça, notadamente ao Ministério Público e ao Poder Judiciário, o controle de políticas públicas em face de situações de injustificável comportamento estatal (comissivo, omissivo ou parcialmente omissivo) quanto à efetivação de direitos sociais assegurados constitucionalmente.

É que, apesar de competir primariamente aos Poderes Legislativo e Executivo a elaboração e execução de políticas públicas, cabe ao Ministério Público, no exercício de suas funções institucionais, ${ }^{3}$ e ao Poder Judiciário, no exercício da jurisdição - inafastável quanto à possibilidade de apreciação de lesão ou ameaça a

\footnotetext{
${ }^{1}$ São esclarecedoras, a respeito, as lições de Maria Paula Dallari Bucci (2001, p. 10): "O problema da justiciabilidade dos direitos sociais se alarga muito, passando a abarcar todo o caminho de efetivação de um direito, desde o seu nascimento, quando é previsto na norma, até a sua emancipação, quando é encartado em determinado programa de ação de um governo e passa a integrar medidas de execução. Em outras palavras, a exigibilidade de um direito aparece nas várias fases de organização temporal da política pública, desde o estabelecimento da agenda (agenda setting), a formulação de alternativas, a decisão, a implementação da política, a execução até a fase final, da avaliação". "Podese partir de uma definição provisória de políticas públicas como programas de ação governamental voltados à concretização de direitos. [...] Há uma estreita relação entre os temas das políticas públicas e dos direitos humanos. Pois uma das características do movimento de ampliação do conteúdo jurídico da dignidade humana é a multiplicação das demandas por direitos, demandas diversificadas e pulverizadas na titularidade de indivíduos" (BUCCI, 2001, p. 13). Em texto mais recente, a autora apresentou definição mais elaborada: "Políticas públicas são programas de ação governamental visando a coordenar os meios à disposição do Estado e as atividades privadas, para a realização de objetivos socialmente relevantes e politicamente determinados" (BUCCI, 2006, p. 241).

${ }^{2}$ Note-se que a questão é eminentemente constitucional, pois envolve a inafastabilidade da jurisdição, a separação dos Poderes, a eficácia dos direitos fundamentais sociais etc.

${ }^{3} \mathrm{Em}$ especial: art. 127, caput, da Constituição (BRASIL, 1988): "defesa da ordem jurídica, do regime democrático e dos interesses sociais e individuais indisponíveis"; e art. 129, II e III, da Constituição: "zelar pelo efetivo respeito dos Poderes Públicos e dos serviços de relevância pública aos direitos assegurados nesta Constituição, promovendo as medidas necessárias a sua garantia"; e "promover o inquérito civil e a ação civil pública, para a proteção do patrimônio público e social, do meio ambiente e de outros interesses difusos e coletivos".
} 
direito, art. 50 XXXV, da Constituição (BRASIL, 1988) -, promoverem o cumprimento da Constituição, na efetivação de políticas públicas nela previstas, em casos de comportamentos estatais descumpridores, de modo irrazoável, das normas respectivas.

A legitimidade, assim, para tal atuação do Ministério Público e do Poder Judiciário - atividade que, sem dúvida, se reveste de caráter excepcional, porquanto, como frisado, a execução das políticas públicas constitucionalmente previstas incumbe primariamente aos Poderes Legislativo e Executivo - é conferida pelo próprio texto constitucional (BRASIL, 1988), expressão máxima do poder soberano popular no art. $1^{0}$, parágrafo único.

Note-se, de resto, que não se cuida de controle judicial do mérito administrativo (discricionariedade); o controle é de legalidade lato sensu, ou seja, de juridicidade. É dizer, a atuação ministerial e judicial não pode fundamentar-se em critérios de conveniência e oportunidade, mas apenas em normas (princípios e regras).

Ademais, a Constituição estabelece que "[a]s normas definidoras dos direitos e garantias fundamentais têm aplicação imediata", art. 50, § $1^{\circ}$ (BRASIL, 1988), a propósito, confira-se a obra de Sarlet (2008, p. 13 e 20).

Há, pois, em verdade, possibilidade de atuação somente para remediar abusos governamentais, garantindo-se a supremacia da Constituição. O que disso passar viola o princípio da independência e harmonia entre os Poderes.

Desde a paradigmática decisão proferida pelo Ministro Celso de Mello na Arguição de Descumprimento de Preceito Fundamental n. 45, ADPF 45 MC, Rel. Min. Celso de Mello, j. em 29/4/2004, DJ 4/5/2004 (BRASIL, 2004, p. 12), a Suprema Corte vem sufragando em inúmeras oportunidades a compreensão cristalizada em tal decisão, adotada em linhas gerais neste texto. ${ }^{4} 5$

\footnotetext{
${ }^{4}$ Colhem-se dessa decisão estes ensinamentos (BRASIL, 2004, p. 3-4): "[é] certo que não se inclui, ordinariamente, no âmbito das funções institucionais do Poder Judiciário - e nas desta Suprema Corte, em especial - a atribuição de formular e de implementar políticas públicas (JOSÉ CARLOS VIEIRA DE ANDRADE, "Os Direitos Fundamentais na Constituição Portuguesa de 1976", p. 207, item n. 05, 1987, Almedina, Coimbra), pois, nesse domínio, o encargo reside, primariamente, nos Poderes Legislativo e Executivo. [...] [t]al incumbência, no entanto, embora em bases excepcionais, poderá atribuir-se ao Poder Judiciário, se e quando os órgãos estatais competentes, por descumprirem os encargos político-jurídicos que sobre eles incidem, vierem a comprometer, com tal comportamento, a eficácia e a integridade de direitos individuais e/ou coletivos impregnados de estatura constitucional,
} 


\title{
Isso porque, como se conclui em tal decisão, "[a] negação de qualquer tipo
}

\author{
de obrigação a ser cumprida na base dos direitos fundamentais sociais tem como
} consequência a renúncia de reconhecê-los como verdadeiros direitos".

ainda que derivados de cláusulas revestidas de conteúdo programático. [...] o caráter programático das regras inscritas no texto da Carta Política 'não pode converter-se em promessa constitucional inconsequente, sob pena de o Poder Público, fraudando justas expectativas nele depositadas pela coletividade, substituir, de maneira ilegítima, o cumprimento de seu impostergável dever, por um gesto irresponsável de infidelidade governamental ao que determina a própria Lei Fundamental do Estado' (RT] 175/1212-1213, Rel. Min. CELSO DE MELLO). [...] Não obstante a formulação e a execução de políticas públicas dependam de opções políticas a cargo daqueles que, por delegação popular, receberam investidura em mandato eletivo, cumpre reconhecer que não se revela absoluta, nesse domínio, a liberdade de conformação do legislador, nem a de atuação do Poder Executivo. É que, se tais Poderes do Estado agirem de modo irrazoável ou procederem com a clara intenção de neutralizar, comprometendo-a, a eficácia dos direitos sociais, econômicos e culturais, afetando, como decorrência causal de uma injustificável inércia estatal ou de um abusivo comportamento governamental, aquele núcleo intangível consubstanciador de um conjunto irredutível de condições mínimas necessárias a uma existência digna e essenciais à própria sobrevivência do indivíduo, aí, então, justificar-se-á, como precedentemente já enfatizado - e até mesmo por razões fundadas em um imperativo ético-jurídico - a possibilidade de intervenção do Poder Judiciário, em ordem a viabilizar, a todos, o acesso aos bens cuja fruição Ihes haja sido injustamente recusada pelo Estado. [...] parece-nos cada vez mais necessária a revisão do vetusto dogma da Separação dos Poderes em relação ao controle dos gastos públicos e da prestação dos serviços básicos no Estado Social, visto que os Poderes Legislativo e Executivo no Brasil se mostraram incapazes de garantir um cumprimento racional dos respectivos preceitos constitucionais."

$5 \quad$ Na trilha dessa decisão, com a mesma linha argumentativa, inúmeras outras, monocráticas e colegiadas, foram proferidas pelo STF. A título ilustrativo, indiquem-se alguns acórdãos sobre: $(I)$ implantação da Defensoria Pública no âmbito estadual: AI 598212 ED, Rel. Min. Celso de Mello, 2T, j. em 25/3/2014, DJe-077 23/4/2014; (ii) ampliação e melhoria no atendimento de gestantes em maternidades estaduais: RE 581352 AgR, Rel. Min. Celso de Mello, 2T, j. em 29/10/2013, DJe-230 21/11/2013; (iii) direito à saúde: AI 734487 AgR, Rel. Min. Ellen Gracie, 2T, j. em 3/8/2010, DJe-154 19/8/2010; (iv) segurança pública: RE 628159 AgR, Rel. Min. Rosa Weber, 1T, j. em 25/6/2013, DJe159 14/8/2013; RE 559646 AgR, Rel. Min. Ellen Gracie, 2T, j. em 7/6/2011, DJe-120 22/6/2011; e RE 367432 AgR, Rel. Min. Eros Grau, 2T, j. em 20/4/2010, DJe-086 13/5/2010; (v) gratuidade nos transportes coletivos urbanos aos maiores de 65 anos: AI 707810 AgR, Rel. Min. Rosa Weber, 1T, j. em 22/5/2012, DJe-110 5/6/2012; ( VI) acesso e atendimento em creches e unidades de pré-escola para crianças: ARE 639337 AgR, Rel. Min. Celso de Mello, 2T, j. em 23/8/2011, DJe-177 14/9/2011; e RE 410715 AgR, Rel. Min. Celso de Mello, 2T, j. em 22/11/2005, DJ 3/2/2006; (vii) vaga em estabelecimento de educação infantil: RE 595595 AgR, Rel. Min. Eros Grau, 2T, j. em 28/4/2009, DJe099 28/5/2009; e (viii) transporte de alunos da rede estadual de ensino: RE 603575 AgR, Rel. Min. Eros Grau, 2T, j. em 20/4/2010, DJe-086 13/5/2010. Cf. outros acórdãos do STF sobre a judicialização de políticas públicas: RE 788170 AgR, Rel Min. Cármen Lúcia, 2T, j. em 22/4/2014, DJe-085 6/5/2014; RE 658171 AgR, Rel. Min. Dias Toffoli, 1T, j. em 10/4/2014, Dje-079 25/4/2014; e RE 677524 AgR, Rel. Min. Cármen Lúcia, 1T, j. em 24/4/2012, DJe-096 16/5/2012. No mesmo sentido vem pronunciando-se o Superior Tribunal de Justiça (STJ). Também a título exemplificativo, vejam-se alguns arestos sobre: ( $I$ ) efetivo acesso e atendimento em creches e unidades de pré-escola: EREsp 485969/SP, Rel. Min. José Delgado, 1S, j. em 23/8/2006, DJ 11/9/2006, p. 220); (ii) fornecimento de medicamentos: AgRg no REsp 1107511/RS, Rel. Min. Herman Benjamin, 2T, j. em 21/11/2013, DJe 6/12/2013; (iii) direitos previdenciários: REsp 1309137/MG, Rel. Min. herman benjamin, 2T, j. em 8/5/2012, DJe 22/5/2012; (iv) implementação do modelo de assistência à saúde do índio e instalação material de serviços de saúde à população indígena: REsp 811608/RS, Rel. Min Luiz Fux, 1T, j. em 15/5/2007, D] 4/6/2007, p. 314. 
Impende, porém, traçar limites para o controle feito pelo sistema de Justiça - aí incluído o Ministério Público em sua atuação extrajudicial -, bem como estabelecer a forma processualmente adequada para sua realização.

\section{DIREITOS SOCIAIS, RESERVA DO POSSÍVEL E PRINCÍPIO DA IGUALDADE: APORTE SOBRE CORRUPÇÃO}

Não só os direitos fundamentais de segunda geração ou dimensão (econômicos, sociais e culturais), mas todos os direitos, inclusive os de primeira geração ou dimensão (civis e políticos), requerem custos públicos para sua efetivação, pois todos demandam estrutura estatal para sua garantia, ${ }^{6}$ de sorte que levar os direitos a sério implica que tais custos e a escassez de recursos, a qual naturalmente impõe escolhas, sejam considerados (HOLMES; SUNSTEIN, 1999).

Todavia, é quanto aos direitos sociais, cuja concretização exige mais clara e intensamente prestações estatais, que a necessidade de recursos públicos e sua escassez se faz mais sentir. Isso não pode ser olvidado sob a argumentação de que a justiciabilidade desses direitos e sua aplicabilidade imediata foram constitucionalmente garantidas. A realidade impõe-se: os recursos são finitos e escolhas precisam ser feitas para sua alocação e consequente materialização de direitos. "O grau de desenvolvimento socioeconômico de cada país impõe limites, que o mero voluntarismo de bacharéis não tem como superar" (SARMENTO, 2010, p. 181). De fato, "[c]ada decisão explicitamente alocativa de recursos envolve também, necessariamente, uma dimensão implicitamente desalocativa" (SARMENTO, 2010, p. $182)^{7}$

Daí o surgimento da noção de "reserva do possível", expressão de origem alemã ${ }^{8}$ que ordinariamente é compreendida em três dimensões: ( $I$ ) possibilidade fática da prestação, isto é, disponibilidade material de recursos financeiros; (ii)

\footnotetext{
${ }^{6} \mathrm{O}$ direito de propriedade, por exemplo, tradicionalmente classificado como negativo, só pode ser protegido se houver segurança pública, sistema judiciário, ou seja, prestações positivas estatais (HOLMES; SUNSTEIN, 1999).

7 É também a lição de Ingo Sarlet (2008, p. 20): "Justamente pelo fato de os direitos sociais na sua condição (como vimos, não exclusiva!) de direitos a prestações terem por objeto prestações estatais vinculadas diretamente à destinação, distribuição (e redistribuição), bem como à criação de bens materiais, aponta-se, com propriedade, para sua dimensão economicamente relevante".

8 "A expressão 'reserva do possível' foi difundida por uma célebre decisão da Corte Constitucional alemã proferida em 1972, e conhecida como o caso Númerus Clauus" (SARMENTO, 2010, p. 196).
} 
possibilidade jurídica, ligada à existência de previsão orçamentária (legalidade da despesa) e competência do ente político para sua execução; e (iii) razoabilidade da pretensão do titular do direito (SARLET, 2008, p. 22-24; SARMENTO, 2010, p. 196202). ${ }^{9}$

É certo, por outro lado, que, tendo em vista não só a aplicabilidade imediata dos direitos fundamentais e sua centralidade em nossa ordem constitucional, mas também por se tratar de fato impeditivo do direito alegado, art. 373, II, do Código de Processo Civil (CPC), incumbe ao Poder Público o ônus da prova relativamente à alegação de reserva do possível, até porque, de resto, tal comprovação é muito mais fácil para sua defesa, que detém todas as informações a respeito, do que para o demandante (art. 373, § 10, do CPC) (SARLET, 2008, p. 28; SARMENTO, 2010, p. 200). ${ }^{10}$

${ }^{9}$ Convém observar que a "ausência de previsão orçamentária é um elemento que deve comparecer na ponderação de interesses [...], mas que está longe de ser definitivo, podendo ser eventualmente superado de acordo com as peculiaridades do caso" (SARMENTO, 2010, p. 202). Já a insuficiência material de recursos constitui limite insuperável. É que, como enfaticamente aponta Flávio Galdino (2005) já no subtítulo de seu livro sobre os custos dos direitos, "direitos não nascem em árvores".

10 Há controvérsia sobre a possibilidade ou não de alegação da reserva do possível em face do chamado "mínimo existencial" - independentemente de a definição desse mínimo dar-se a priori (teoria absoluta) ou a posteriori (teoria relativa), ou seja, se há um conteúdo mínimo previamente determinado de cada direito fundamental social ou se esse conteúdo essencial depende de ponderação à luz de cada caso (COSTA, 2013, p. 349-350; SARMENTO, 2010, p. 202-207). O Projeto de Lei n. 8058/2014, em trâmite na Câmara dos Deputados para instituir "processo especial para o controle e intervenção em políticas públicas pelo Poder Judiciário" (BRASIL, 2014a), define mínimo existencial em seu art. 70, parágrafo único, como "o núcleo duro, essencial, dos direitos fundamentais sociais garantidos pela Constituição Federal, em relação ao específico direito fundamental invocado, destinado a assegurar a dignidade humana". Esse Projeto apresenta inúmeros avanços para o adequado controle judicial de políticas públicas. O respectivo Anteprojeto foi encetado pelo Centro Brasileiro de Estudos e Pesquisas Judiciais (CEBEPEJ), presidido por Ada Pellegrini Grinover e Kazuo Watanabe, após amplos estudos e debates acadêmicos (GRINOVER; WATANABE, 2013, p. 506-508). Apesar de relevante doutrina (p. ex., SARLET, 2008, p. 34), com significativo eco na jurisprudência (cf., além da já citada decisão proferida pelo Ministro Celso de Mello na ADPF 45 MC: STF, RE 581352 AgR, Rel. Min. Celso de Mello, 2T, j. em 29/10/2013, DJe-230 21/11/2013; STF, ARE 639337 AgR, Rel. Min. Celso de Mello, 2T, j. em 23/08/2011, DJe-177 14/9/2011; e STJ, REsp 811608/RS, Rel. Min. Luiz Fux, 1T, j. em 15/5/2007, DJ 4/6/2007, p. 314.), no sentido da inoponibilidade, parece que a falta real de recursos pode constituir, em tese, obstáculo insuperável também à materialização mínimo existencial relacionado a dado direito social. A oposição exitosa dessa matéria de defesa pelo Poder Público, porém, em se tratando de demanda voltada à proteção do núcleo essencial de um direito social, requer demonstração de que os recursos públicos estão sendo utilizados para prestações de igual ou maior relevância constitucional. Essa é a conclusão extraída dos objetivos da Constituição da República, que por certo devem nortear a arrecadação e despesas do Poder Público, como bem indicou o Ministro Celso de Mello na ADPF 45, ao secundar o escólio de Ana Paula de Barcellos. É também essa a posição de Daniel Sarmento (2010, p. 207, grifo nosso): "não me parece que o mínimo existencial possa ser assegurado judicialmente de forma incondicional, independentemente de considerações acerca do custo de universalização das prestações demandadas. Porém, entendo que quanto mais indispensável se afigurar uma determinada prestação estatal para a garantia da vida 
Noutra perspectiva, aporte pouquíssimo explorado, mas pertinente para o exame da reserva do possível, diz respeito à corrupção. ${ }^{11}$

Regis Fernandes de Oliveira chama a atenção para a caracterização da corrupção como gravíssima agressão aos direitos fundamentais sociais à saúde, educação, habitação etc., cuja concretização resta significativamente prejudicada pelo desvio dos recursos públicos disponíveis (2014, p. 402-403). ${ }^{12}$

De fato, a ONU estima um desperdício de $5 \%$ do PIB mundial por corrupção (NAÇÕES UNIDAS BRASIL, 2017). ${ }^{13}$ Ademais, no ranking da Transparência Internacional Brasil (2018) dos países menos corruptos do mundo (Corruption Perceptions Index), o Brasil figura na vexatória $105^{a}$ posição.

Para ter-se uma ideia do que essa estimativa de $5 \%$ representa em relação ao Brasil, apenas no exercício financeiro de 2017, em que o PIB foi de 6,6 trilhões (BÔAS; SARAIVA, 2018), o espantoso montante estimado de recursos desviados por corrupção é de $\mathrm{R} \$ 330$ bilhões. ${ }^{14}$

Esse valor equivale a três vezes o total do orçamento federal em saúde no exercício de 2017 ( $R \$ 110,2$ bilhões) e também acerca do triplo do total do orçamento federal em educação no mesmo exercício financeiro ( $R$ \$ 111,3 bilhões) (BRASIL, 2016). Em outra comparação ilustrativa, esses R\$330 bilhões correspondem a mais ou menos 110 vezes o investimento federal em ciência e tecnologia também no exercício de 2017 (cerca de R\$ 3 bilhões) (BRASIL, 2017).

digna do jurisdicionado, maior deve ser o ônus argumentativo imposto ao Estado para superar o direito prima facie garantido. Será praticamente impossível, por exemplo, justificar a não extensão do saneamento básico para uma determinada comunidade carente, quando o Poder Público estiver gastando maciçamente com publicidade ou obras faraônicas".

${ }^{11}$ Cf., a propósito: LEAL, 2014 - estudo oportuno sobre os possíveis reflexos da corrupção na análise do princípio da reserva do possível, com conclusões, porém, ainda incipientes, pela novidade da temática.

${ }^{12}$ Convém observar que, apesar de a maioria dos cidadãos indignar-se com a corrupção, são os mais pobres que sofrem seus mais duros e nefastos impactos, pois mais dependem do serviço de saúde do SUS, da educação prestada nas escolas públicas, de implementação de saneamento básico em suas cidades e bairros e outros serviços públicos essenciais para a concretização de direitos fundamentais em que os valores desviados deveriam ser investidos.

${ }^{13}$ Semelhantemente, estudos de Paolo Mauro (economista do FMI) e Marcos Fernandes Gonçalves da Silva (publicado pelo SENAC) estimam um desperdício de $5 \%$ a $10 \%$ do PIB mundial com perdas ou desvios dos cofres públicos (OLIVEIRA, 2014).

${ }^{14} \mathrm{Em}$ relação à solidez da reportada estimativa de 5\% do PIB desviados em corrupção, resultante dos referidos estudos, é de lembrar que, apenas nos processos iniciados pelo Ministério Público Federal na primeira instância da Justiça Federal em Curitiba e no Rio de Janeiro no âmbito da Operação Lava Jato - casos judiciais que envolvem em sua maioria somente atos de corrupção em uma única empresa estatal, a Petrobras -, busca-se o ressarcimento de cerca de R $\$ 45$ bilhões (BRASIL, 2018a, 2018b). 
Com menos da metade desse montante, poder-se-ia resolver o sério déficit de saneamento básico no Brasil, segundo estudo da Agência Nacional de Águas (AGÊNCIA CÂMARA NOTÍCIAS, 2017). ${ }^{15}$

Bem se nota, portanto, a pertinência da identificação entre corrupção e violação gravíssima a direitos fundamentais sociais, pois os vultosos desvios de recursos públicos perpetrados cotidianamente no país impedem que o Estado concretize direitos inerentes à vida digna assegurados na Constituição. ${ }^{16}$

Emerson Garcia também já teve ensejo de frisar essa nefasta relação: "Esse ciclo conduz ao estabelecimento de uma relação simbiótica entre corrupção e comprometimento dos direitos fundamentais do indivíduo. Quanto maiores os índices de corrupção, menores serão as políticas públicas de implementação dos direitos sociais. Se os recursos estatais são reconhecidamente limitados, o que torna constante a invocação da reserva do possíve/ ao se tentar compelir o Poder Público a concretizar determinados direitos consagrados no sistema, essa precariedade aumentará na medida em que os referidos recursos, além de limitados, tiverem redução de ingresso ou forem utilizados para fins ilícitos" (GARCIA, 2003).

À vista desse cenário, é de pensar seriamente sobre a consideração, quando da análise da alegação de reserva do possível, dos esforços - ou da ausência destes - do ente político no sentido de prevenir e combater a corrupção, por meio de medidas comprovadas no processo. ${ }^{17}$

15 "No Brasil, 43\% da população possui esgoto coletado e tratado e $12 \%$ utilizam-se de fossa séptica (solução individual), ou seja, $55 \%$ possuem tratamento considerado adequado; $18 \%$ têm seu esgoto coletado e não tratado, o que pode ser considerado como um atendimento precário; e $27 \%$ não possuem coleta nem tratamento, isto é, sem atendimento por serviço de coleta sanitário. [...] A implementação das soluções de esgotamento e os investimentos serão feitos de forma gradual. No horizonte de 2035 foi estimado o valor de R\$149.5 bilhões em obras de coleta e tratamento dos esgotos para os 3 grupos, com foco na universalização do esgotamento sanitário e na proteção dos recursos hídricos e no seu uso sustentável" (AGÊNCIA CÂMARA NOTÍCIAS, 2017).

${ }^{16}$ Regis Fernandes de Oliveira (2014) também enfrenta e refuta oportunamente a ideia de que a corrupção seria fator de desenvolvimento econômico e social, a qual remonta aos escritos de Bernard de Mandeville (em A Fábula das Abelhas ou Vícios Privados, Benefícios Públicos) e grassa, ainda que timidamente, no meio jurídico no sentido de que a corrupção serviria como uma "graxa na engrenagem da máquina", o que, do ponto de vista econômico, seria tolerável. É o popular "rouba, mas faz". A referência a estudos que, com base em evidências empíricas, mostram que a corrupção reduz o crescimento econômico e os investimentos faz essa malsinada ideia cair por terra.

17 Felipe Dutra Asensi (2013, p. 110) chega a acenar para essa abordagem: "Um terceiro equívoco refere-se à inexistência de ônus da prova de quem utiliza o argumento da reserva do possível. Ao ser ingenuamente reproduzido como um dogma, isto é, como um ponto de partida inquestionável, desaparece o dever do Estado de provar que realmente não possui recursos financeiros para uma determinada política. Não bastando a tentativa de restringir direitos ou de situar um cidadão contra o 
Por outro lado, cumpre enfrentar dramático problema decorrente da judicialização de políticas públicas no Brasil: em se tratando de direitos sociais, econômicos e culturais que surgiram historicamente para a efetivação do princípio da igualdade (BONAVIDES, 2008, p. 564), sua indiscriminada judicialização em processos individuais tende $a$, paradoxalmente, violar a isonomia.

É que, como muitas vezes se dá em relação ao direito à saúde, por exemplo, determina-se ao Estado dada prestação dirigida a uma única pessoa beneficiada, cujos custos não permitiriam, entretanto, sua universalização.

Em acréscimo, o acesso individual à justiça muitas vezes não se concretiza para os mais pobres e menos instruídos. Deveras, "o acesso à justiça no Brasil está longe de ser igualitário. Por diversas razões, os segmentos mais excluídos da população dificilmente recorrem ao Judiciário para proteger seus direitos", de sorte que decisões individuais equivocadas podem "criar privilégios não universalizáveis" (SARMENTO, 2010, p. 182-183). ${ }^{18}$

Portanto - e, esta, é a primeira e talvez mais forte razão para a tese defendida neste estudo e melhor fundamentada em item à frente -, é de todo conveniente e até necessária a coletivização dessa tutela judicial, pois, à luz do princípio da igualdade, a reserva do possível deve ser apreciada em face da possibilidade de universalização do direito social discutido, ou seja, de atendimento a todos que estão na mesma situação (COSTA, 2013).

Nesse sentido, Daniel Sarmento salienta que a análise da reserva do possível não pode pautar-se no "custo representado apenas pela prestação concedida ao autor da ação" (2010, p. 182). É que, "por mais custosa que seja esta prestação,

outro, a reserva do possível ainda é usada como um dado e sem qualquer discussão séria e aprofundada sobre o motivo pelo qual não há determinado recurso. Não há por conta de alocação ineficiente? Ou porque houve corrupção? Ou será que houve eleição equivocada de prioridades? 0 problema foi de gestão ineficiente? Ou realmente não há recursos porque a arrecadação tributária foi insuficiente?".

18 O modelo de litigância individual nessa seara acaba então por agravar aquilo que Boaventura de Souza Santos chama de predominância estrutural dos processos de exclusão sobre os de inclusão social. O autor português leciona que esses processos revelam-se por duas formas: a) o póscontratualismo, pelo qual grupos e interesses sociais incluídos no contrato social são dele excluídos sem perspectiva de regresso; e b) o pré-contratualismo, pelo qual é bloqueado o acesso à cidadania a grupos que se consideravam candidatos a ela. Os assim excluídos do contrato social moderno, apesar de formalmente cidadãos, são lançados, de fato, num estado de natureza, em permanente ansiedade em relação ao presente e futuro, num caos constante em relação aos atos mais simples de sobrevivência e convivência, com o risco de surgimento de diversos fenômenos agrupados pelo autor sob a denominação fascismo societal (SANTOS, 1999, p. 33-75). 
dificilmente ela será muito significativa quando cotejada com a magnitude dos recursos e orçamentos das entidades federativas. Assim, se o parâmetro for este, praticamente toda pretensão formulada em ações individuais será acolhida, ainda quando seja economicamente impossível para o Estado estender o mesmo benefício a todas as pessoas em idêntica situação. Ocorre que o Estado não deve conceder a um indivíduo aquilo que ele não tiver condições de dar a todos os que se encontrarem na mesma posição. Esta é uma exigência fundamental imposta pelo princípio da igualdade, que não pode ser postergada" (SARMENTO, 2010, p. 199). ${ }^{19}$

A tutela jurisdicional individual por certo deve ser prestada nos casos em que o arcabouço jurídico da política pública relacionada ao direito social vindicado estiver suficientemente delineado. Em tais casos, o titular do direito apenas exige o cumprimento das normas que Ihe garantem especificamente determinada prestação estatal descumprida - por exemplo, não fornecimento pelo SUS de dado medicamento que deveria fornecer, conforme sua Relação Nacional de Medicamentos Essenciais (RENAME). Não há aí propriamente controle judicial da política pública, que permanece intacta, e tampouco qualquer ofensa à isonomia. Há apenas tutela do direito subjetivo a prestação estatal cabalmente definida no ordenamento jurídico. Genuíno controle judicial de política pública, no entanto, sucede, por exemplo, com a determinação de fornecimento de medicamento não incluído na RENAME, pois aí há modificação da política. É para esse último tipo de situação que o controle judicial individual mostra-se inadequado, não apenas à luz do princípio da igualdade, que inspirou o surgimento dos direitos sociais, mas também por outros motivos à frente expostos.

\footnotetext{
${ }^{19}$ Especificamente sobre o direito à saúde, Luís Roberto Barroso (2008, p. 27) segue idêntica linha de raciocínio: "As políticas públicas de saúde devem seguir a diretriz de reduzir as desigualdades econômicas e sociais. Contudo, quando o Judiciário assume o papel de protagonista na implementação dessas políticas, privilegia aqueles que possuem acesso qualificado à Justiça, seja por conhecerem seus direitos, seja por poderem arcar com os custos do processo judicial. Por isso, a possibilidade de o Judiciário determinar a entrega gratuita de medicamentos mais serviria à classe média que aos pobres. Inclusive, a exclusão destes se aprofundaria pela circunstância de o Governo transferir os recursos que lhes dispensaria, em programas institucionalizados, para o cumprimento de decisões judiciais, proferidas, em sua grande maioria, em benefício da classe média".
} 


\subsection{Outras críticas ao controle judicial de políticas públicas}

Além da incompatibilidade do modelo de litigância individual com o princípio da igualdade, a judicialização ora analisada tem recebido outras críticas bastante contundentes, sintetizadas por Diogo Rosenthal Coutinho: (a) o Judiciário não está estruturado para promover mudanças sociais abrangentes e corrigir adequadamente o rumo de políticas públicas desde uma óptica substantiva ou distributiva; (b) essas políticas requerem medidas legislativas e complexas ações administrativas que dependem, em última instância, de combinação de ações políticas e expertise técnica para as quais o Judiciário não é capacitado, vocacionado ou legitimado; (c) decisões sobre políticas públicas demandam arrecadação e alocação de volumes de recursos significativos e de decisões alocativas baseadas numa visão alargada do universo das políticas públicas, que o Judiciário não possui; e (d) as decisões judiciais isoladas sobre políticas públicas podem minar sua racionalidade (2013, p. 192).

Com exceção da referência à legitimidade do sistema de Justiça para o controle de políticas públicas - legitimidade conferida diretamente pela ordem constitucional, como exposto no item $2-$, afiguram-se pertinentes às críticas levantadas.

Além da já tratada ofensa à isonomia, é séria a objeção relativa à falta de estrutura e expertise do Judiciário para o trato desses casos. ${ }^{20}$

São significativas, outrossim, as dificuldades do sistema de Justiça para, a partir de uma visão de conjunto, tomar decisões com impactos na arrecadação e alocação de volumosos recursos públicos: "[o] processo judicial foi pensado com foco nas questões bilaterais da justiça comutativa [...]. Contudo, a problemática subjacente aos direitos sociais envolve sobretudo questões de justiça distributiva, de natureza multilateral, já que, diante da escassez, garantir prestações a alguns

20 É o que também assinala com propriedade Daniel Sarmento (2010, p. 208): "A realização dos direitos sociais pelo Estado dá-se através de políticas públicas, cuja elaboração e implementação dependem, para seu êxito, do emprego de conhecimentos específicos. Os poderes Executivo e Legislativo (mais o primeiro que o segundo) possuem em seus quadros pessoas com a necessária formação especializada para assessorá-los na tomada das complexas decisões requeridas nesta área, que frequentemente envolvem aspectos técnicos, econômicos e políticos diversificados. O mesmo não ocorre no Judiciário". 
significa retirar recursos do bolo que serve aos demais. Boas decisões nesta área pressupõem a capacidade de formar uma adequada visão de conjunto, o que é muito difícil de se obter no âmbito de um processo judicial" (COUTINHO, 2013, p. 210).21

Pois bem, como, então, equacionar a importante questão posta, isto é, viabilizar o controle jurisdicional e a aplicabilidade imediata dos direitos fundamentais sociais, garantidos constitucionalmente (art. 50, XXXV e $\S 1^{\circ}$ ), mas evitar as distorções que a atuação do Judiciário na seara das políticas públicas pode ocasionar?

\section{ADEQUAÇÃO DO PROCESSO COLETIVO PARA O CONTROLE DE POLÍTICAS PÚBLICAS: REFERÊNCIA AO INTERESSE PROCESSUAL}

A solução para a questão deixada ao final do segmento anterior encontrase na instrumentalidade processual: o processo deve servir à adequada tutela do direito subjetivo material, com suas especificidades, também em sede de políticas públicas.

Com o reconhecimento da força normativa da Constituição e diante dos compromissos que, a partir da metade do último século, foram incorporados gradativamente aos textos constitucionais, o sistema processual deixou de ser encarado como simples instrumento de atuação da vontade concreta da lei (CHIOVENDA, 2000, p. 56), para tornar-se efetivo mecanismo voltado à tutela de direitos, especialmente daqueles constitucionalmente assegurados (MARINONI, 2017, p. 25).

A Constituição garante que a lei (seja sua presença ou omissão) jamais impedirá que uma lesão (concreta ou potencial) a direito seja excluída da apreciação jurisdicional (art. 50, XXXV). Logo, o "processo deve se estruturar de maneira

\footnotetext{
${ }^{21}$ Nesse sentido, em requerimento de realização de audiência pública, formulado pelos Deputados Esperidião Amin e Paulo Teixeira, para debater o já referido Projeto de Lei n. 8058/2014 - que "institui processo especial para o controle e intervenção em políticas públicas pelo Poder Judiciário" - , informa-se que decisões judiciais individuais consumiram cerca de $25 \%$ do orçamento catarinense disponível para área da saúde (excluídas as despesas com pessoal) em 2015 - dado apresentado por João Paulo Kleinubing, Secretário de Saúde do Estado de Santa Catarina, em Audiência Pública da Câmara dos Deputados, ocorrida em 1\%/09/2015 - e, para 2016, o Ministério da Saúde estimava que essas decisões demandariam do SUS entre R\$ 5 e R\$ 7 bilhões, nos três níveis federativos - informação prestada por Arionaldo Bonfim Rosendo, Subsecretário de Planejamento e Orçamento do Ministério da Saúde, em Audiência Pública da Câmara dos Deputados, ocorrida em 29/8/2016 (BRASIL, 2014a).
} 
tecnicamente capaz de permitir a prestação das formas de tutela prometidas pelo direito material. De modo que entre as tutelas dos direitos e as técnicas processuais deve haver uma relação de adequação" (MARINONI, 2017, p. 28).

Para o controle judicial de políticas públicas relativas à concretização de direitos sociais, a mesma lógica tem lugar. "[S]ão necessárias adaptações da técnica processual para a tutela adequada dos direitos sociais fundamentais [...]. Algumas adaptações já são possíveis [...]. Outras demandam a alteração legislativa" (COSTA, 2013, p. 346).

Os direitos sociais podem ter titularidade simultaneamente individual e transindividual, a depender da perspectiva da abordagem e das circunstâncias do caso (SARLET, 2016). Como exposto ao final do item 3, a tutela jurisdicional individual é devida nos casos em que o desenho jurídico da política pública relativa ao direito social pleiteado estabelecer determinada prestação estatal - hipótese em que não há verdadeiro controle judicial da política pública, que permanece intacta, pois se exige apenas o cumprimento das normas que garantem a prestação estatal inadimplida.

De outro lado, à luz das críticas e problemas acima apresentados relativamente ao controle judicial (criação ou modificação) de políticas públicas, resta claro que o modelo processual individual não se mostra adequado. A quebra da isonomia, a falta de estrutura e expertise do Judiciário e a ausência de visão de conjunto quanto aos impactos na arrecadação e alocação de recursos públicos geram disfunções insuperáveis num modelo de litigância individual desenfreada. "[N]ão é possível resolver questões de justiça distributiva em um modelo processual individualista, que trabalha com questões de justiça cumutativa" (COSTA, 2013, p. 355).

O Fórum da Saúde, instituído pelo Conselho Nacional de Justiça, em levantamento parcial da quantidade de processos relativos ao SUS em tramitação, em junho de 2014, na Justiça Federal e nas Justiças Estaduais - sem computar os feitos no STF e STJ -, encontrou o significativo número de 392.921 processos (BRASIL, 2014b). ${ }^{22}$

${ }^{22}$ Alguns tribunais não disponibilizaram os respectivos números. 
É patente a inviabilidade de, nessa miríade de processos individuais, o Judiciário fazer a contento, em cada caso, o complexo exame imanente ao controle de dada política pública, garantindo a necessária igualdade.

As novas técnicas de julgamento de casos repetitivos - recursos excepcionais repetitivos e incidente de resolução de demandas repetitivas (art. 928 do novo CPC) - mitigam, mas não resolvem o problema, pois geram precedentes obrigatórios para o próprio Judiciário mas não vinculam o Poder Executivo. Assim, caso este não se adéque espontaneamente ao precedente, novas ações judiciais inexoravelmente serão aforadas.

Já o processo coletivo - como se dá também com o controle concentrado e abstrato de constitucionalidade - mostra-se muito mais adequado ao controle de políticas públicas, com a prestação de tutela jurisdicional apta a resolver a questão de forma geral e isonômica, para todos os que se encontrem na mesma situação, no mais das vezes com decisões a serem cumpridas diretamente pelo Poder Executivo, sem necessidade de novas ações judiciais. ${ }^{23}$

${ }^{23}$ Os efeitos da sentença coletiva e, por conseguinte, a respectiva coisa julgada (nas hipóteses em que esta exsurge) operam erga omnes (ZAVASCKI, 2011, p. 64-65; MAZZILLI, 2009, p. 560-561; MARINONI; ARENHART, 2004, p. 812). O art. 16 da LACP, com a restrição inserida pela MP 1.5705/1997 (convertida na Lei 9.494/1997), não configura óbice nem debilita a tese apresentada neste artigo, pois, no sistema integrado de tutela coletiva, a competência territorial (art. $2^{\circ}$ da LACP, combinado com o art. 93 do CDC) abrange toda a extensão do dano (ocorrido ou potencial) que compõe a causa de pedir da demanda, de sorte que os limites do dano determinam os da competência, que, por seu turno, definem o alcance dos efeitos da sentença e a abrangência da coisa julgada (MAZZILLI, 2009, p. 562). Em sentido semelhante: MANCUSO, 2007, p. 300; GRINOVER, 2007, p. 941-943; e RODRIGUES, 2009, p. 272-273. No STJ, essa interpretação, após virada jurisprudencial marcada pelo julgamento do recurso especial repetitivo n. 1243887/PR (Rel. Ministro LUIS FELIPE SALOMÃO, CORTE ESPECIAL, julgado em 19/10/2011, DJe 12/12/2011), passou paulatinamente a predominar na Corte - cf., a título ilustrativo: REsp 1391198/RS, Rel. Min. Luis Felipe Salomão, 2S, j. em 13/8/2014, DJe 2/9/2014; AgInt no REsp 1676719/PR, Rel. Min. Marco Aurélio Bellizze, 3T, j. em 27/2/2018, DJe 09/03/2018; AgInt no REsp 1549608/SC, Rel. Min. Francisco Falcão, 2T, j. em 16/11/2017, DJe 22/11/2017; EDcl no AgInt no AREsp 965.951/PR, Rel. Min. Marco Aurélio Bellizze, 3T, j. em 25/4/2017, DJe 8/5/2017; e REsp 1614263/RJ, Rel. Min. Herman Benjamin, $2 T$, j. em 18/8/2016, DJe 12/9/2016. Sobre as várias e veementes críticas à atual redação do art. 16 da LACP, vale conferir, quanto a: ( $I$ ) sua vigência, ineficácia e inocuidade, em face do art. 103 do CDC (NERY JR.; NERY, 2010, p. 1473-1475; DIDIER JR.; ZANETI JR., 2014, v. 4, p. 159-166); (ii) sua inconstitucionalidade, seja pela ausência dos pressupostos constitucionais para a edição de medida provisória - não havia relevância e urgência, mormente porque o texto original vigorava há doze anos sem impugnação -, seja por afronta aos princípios do acesso à justiça, inclusive por meio de ação civil pública (art. 129, III, da CR), e da proporcionalidade (MAZZILLI, 2009, p. 275; NERY JR.; NERY, 2010, p. 1474; e DIDIER JR; ZANETI JR, 2014, v. 4, p. 159-166) - o STF, porém, não concedeu liminar em controle concentrado para suspender o efeito do preceptivo (STF, Pleno, ADI 1576 MC, Rel. Min. Marco Aurélio, j. em 16/04/97, DJ 6/6/03, p. 29.); (iii) seu caráter absurdo e ilógico, contrário aos mais evidentes fundamentos e objetivos da tutela coletiva (MANCUSO, 2007, p. 300 e 310; MAZZILLI, 2009, p. 276-277; GRINOVER, 2007, p. 939; MARINONI; ARENHART, 2004, p. 818; 
Afora isso, num processo coletivo, diferentemente do que se dá com o semnúmero de processos individuais, é possível adotar mecanismos de democratização da decisão pela participação dos grupos envolvidos, por meio de audiências públicas e intervenção de amicus curiae, o que auxilia também no fornecimento de respaldo técnico para a tomada de decisões complexas de forma bem embasada (GRINOVER; WATANABE, 2013, p. 506; SARMENTO, 2010, p. 211; COSTA, 2013, p. 367.). ${ }^{24}$

Acresça-se que, dadas as características da intervenção em políticas públicas, há sensível ampliação do ônus argumentativo do julgador, que deve motivar minuciosamente suas conclusões, abarcando a complexidade dos valores envolvidos e as consequências materiais da decisão, permitindo, assim, maior controle social da atividade jurisdicional (COSTA, 2013, p. 352 e 366). Ora, é certo que, considerado o grande volume de processos que assoberbam o Judiciário, é inviável esse tipo qualificado de fundamentação em todos os processos individuais que impactam políticas públicas; já nos processos coletivos, em número muito menor, isso é possível. É de ver, ainda, que, em casos individuais, essa fundamentação mais profunda e cuidadosa dificilmente se impõe, pois o foco de atenção está apenas na situação do demandante: "[n]as ações individuais, o raciocínio judicial deveria ser o mesmo. Contudo, aqui é muito mais fácil para o juiz "tapar o sol com a peneira", e conceder "com o coração" qualquer prestação demandada, já que os efeitos concretos de cada decisão sobre o orçamento público costumam ser diminutos [...]. Ocorre que estas decisões tendem a se multiplicar, comprometendo a racionalidade das políticas públicas e criando implicitamente preferências para algumas pessoas sobre bens escassos, fora de qualquer parâmetro ético ou jurídico" (SARMENTO, 2010, p. 213).

Além disso, na fase satisfativa de um processo coletivo acerca de política pública, muito mais complexa que a fase executiva de um processo individual, cumpre estabelecer um plano de ação, com prazos e certa margem para adaptações, com a participação do Ministério Público e do Executivo, exercendo aí o juiz uma função eminentemente mediadora. Não é possível, em regra, em processos com 
essas características, a execução mediante simples ordem de cumprimento da decisão (COSTA, 2013, p. 353). ${ }^{25}$

Há outro aspecto da tutela coletiva que não pode ser ignorado: o Ministério Público costuma instaurar inquérito civil para colher, a partir de amplo poder instrutório - com realização de audiências públicas, requisição de documentos e perícias, oitiva de especialistas etc. -, elementos de convicção para o exercício de suas atribuições para promover a tutela de direitos cuja defesa Ihe caiba. Ainda que constatada a violação do direito ao final dessa instrução, nem sempre a solução será o ajuizamento de ação civil pública. Em muitos casos, a solução é encontrada extrajudicialmente, por meio da celebração de compromisso de ajustamento de conduta ou expedição e acatamento de recomendação, por exemplo. Em sede de políticas públicas, esse modelo de tutela extrajudicial, que depende da participação e consentimento do Poder Público (solução consensual), pode satisfatoriamente resolver a situação de injuridicidade, evitando, ainda, aumento do volume de demandas judiciais.

Pois bem, percebe-se sem dificuldade que, em todas as centenas de milhares de ações individuais, essa fase pré-processual, toda a complexa cognição judicial, inclusive na fase executiva, bem como a ampliação do contraditório para a democratização do processo não são possíveis. É inviável, de resto, levantar-se em cada processo individual o número de pessoas na mesma situação do demandante, os recursos disponíveis, as dificuldades técnicas para a implantação ou alteração da política pública respectiva etc.

\footnotetext{
${ }^{25}$ Exemplo interessante dessa flexibilização na execução da decisão, inclusive com a atribuição a um órgão técnico independente da respectiva atividade fiscalizatória, encontra-se no caso Grootboom, de 2010, no qual a Corte Constitucional da África do Sul decidiu pela possibilidade de controle judicial da razoabilidade da política pública relacionada ao direito à moradia. A Corte determinou que o governo reformulasse essa política de forma a contemplar medidas emergenciais voltadas às pessoas em situação de carência desesperadora (desperate need), sem, porém, precisar as medidas a serem tomadas. E, para o acompanhamento e fiscalização da elaboração e implementação do novo programa, nomeou um órgão técnico independente, de reconhecida expertise e prestígio no país (a Human Rights Commission), que atuou em auxílio e sob a supervisão da Corte (SARMENTO, 2010, p. 211). Nesse sentido, o mencionado Projeto de Lei n. 8058/2014, que trata do processo judicial para controle de políticas públicas, prevê a possibilidade de "acompanhamento do cumprimento das decisões por pessoas físicas ou jurídicas, órgãos ou instituições que atuem sob a supervisão do juiz e em estreito contato com este" (art. 2a , parágrafo único, XI), de modo que, "[p]ara o efetivo cumprimento da sentença ou da decisão de antecipação da tutela, o juiz poderá nomear comissário, pertencente ou não ao Poder Público, que também poderá ser instituição ou pessoa jurídica, para a implementação e acompanhamento das medidas necessárias à satisfação das obrigações, informando ao juiz, que poderá Ihe solicitar quaisquer providências" (art. 19) (BRASIL, 2014a).
} 
Assim, pode-se concluir que, em regra, a prestação adequada de tutela jurisdicional individual em sede de controle de políticas públicas mostra-se virtualmente impossível - a verificação dessa (im)possibilidade deve ocorrer, é claro, caso a caso.

Constatada no caso essa impossibilidade, parece impor-se a extinção do processo sem exame de mérito por falta de interesse processual, em sua vertente utilidade - ou, ainda, por inadequação da via eleita. ${ }^{26}$ Com efeito, que utilidade tem um processo em que é impossível prestar tutela jurisdicional adequada? Nenhuma. Em tal situação, deve o juiz comunicar o Ministério Público e outros legitimados coletivos, para a adequada tutela coletiva.

Essa solução resguarda a inafastabilidade da jurisdição, por meio da tutela coletiva dos direitos sociais - garantida, vale repetir, a tutela individual para as hipóteses em que não há criação ou alteração de política pública, mas mera exigência de prestação especificamente prevista no ordenamento jurídico -, sem, contudo, os inúmeros problemas e distorções causados pela litigância individual de massa.

Essa ideia de ausência de interesse processual - apenas iniciada neste estudo, deixando-se seu desenvolvimento mais aprofundado para outra oportunidade - é potencialmente polêmica, em face do princípio da inafastabilidade da jurisdição. ${ }^{27}$ Sucede, todavia, ser necessária uma "releitura atualizada e contextualizada" desse princípio, "a fim de se preservar sua utilidade e mantê-lo aderente às novas circunstâncias e necessidades da massificada e conflituosa sociedade contemporânea". "Essa releitura é ainda necessária à vista da notória e crescente crise numérica de processos, que avulta muito além da capacidade instalada da Justiça estatal" ${ }^{28}$

\footnotetext{
${ }^{26}$ Embora o novo CPC não tenha tratado, como o revogado, da criticada categoria das condições da ação - ao menos com essa designação -, manteve a exigência de interesse de agir e legitimidade para a causa como requisitos para a apreciação do mérito (arts. 17, 330, II e III, e 337, XI) (NERY JR; NERY, 2010).

${ }^{27}$ Parcela significativa da doutrina vem advogando a preferência da tutela coletiva ora defendida, mas ordinariamente ressalva a possibilidade de tutela individual. Ver, por todos: SARLET, 2016, p. 26.

28 É a lição realista de Rodolfo de Camargo Mancuso (2012). O processualista não cuida do tema ora versado, mas sim de meios não judiciais de resolução de conflitos. Cremos, todavia, que a argumentação encaixa-se também aqui.
} 


\section{CONCLUSÃO}

A justiciabilidade de políticas públicas decorre da vigente ordem constitucional, que garante a inafastabilidade do controle jurisdicional e a aplicabilidade imediata dos direitos fundamentais sociais (art. 50, XXXV e $\S 1^{\circ}$ ).

Por outro lado, a concretização de direitos implica despesas públicas e, ante a limitação dos recursos, escolhas. Assim, a indiscriminada judicialização, em processos individuais, de direitos sociais, econômicos e culturais, que surgiram historicamente para a efetivação do princípio da igualdade, acaba por, paradoxalmente, violar a isonomia, pois, como muitas vezes se dá em relação ao direito à saúde, determina-se ao Estado dada prestação dirigida a uma única pessoa beneficiada, cujos custos não permitiriam, entretanto, sua universalização. Além disso, o acesso individual à justiça muitas vezes não se concretiza para os mais pobres e menos instruídos.

Ademais, a falta de estrutura e expertise do Judiciário e a ausência de visão de conjunto quanto aos impactos na arrecadação e alocação de recursos públicos geram disfunções insuperáveis num modelo de litigância individual desenfreada em tal seara.

Portanto, para garantir a aludida justiciabilidade, mas evitar essas distorções, cumpre, à luz do princípio da instrumentalidade processual, reconhecer a adequação do processo coletivo para a tutela de direitos sociais por meio do controle (criação ou alteração) de políticas públicas.

Em processos coletivos - comumente precedidos de inquérito civil, com possível solução extrajudicial do conflito -, é viável, em cada caso, o complexo exame imanente ao controle de dada política pública (inclusive na fase executiva), garantindo-se a necessária igualdade pela prestação jurisdicional erga omnes, após análise da reserva do possível a partir da possibilidade de universalização da prestação pleiteada, bem como ampliação do contraditório para a democratização do processo por meio de audiências públicas e intervenção de amici curiae, com final fundamentação judicial robusta e minuciosa.

Na miríade de processos individuais, esse tipo de abordagem e análise é inviável, razão pela qual, seja pela inutilidade de um processo em que a tutela 
adequada é virtualmente impossível, seja pela inadequação da via eleita, carecerá, em regra, o demandante individual de interesse de agir. A tutela individual, no entanto, é devida nos casos em que se exige apenas o cumprimento das normas que garantem dada prestação estatal - por exemplo, fornecimento pelo SUS de medicamento listado na RENAME -, situação em que não há real controle judicial da política pública, a qual permanece intacta.

Sem pretensão de esgotar o tema, são essas as contribuições apresentadas para discussão.

\section{REFERÊNCIAS}

AGÊNCIA CÂMARA NOTÍCIAS. Cortes no orçamento de Ciência e Tecnologia podem inviabilizar pesquisas. Brasília, DF: Câmara dos Deputados, 2017. Disponível em: http://www2.camara.leg.br/camaranoticias/noticias/CIENCIA-ETECNOLOGIA/546380-CORTES-NO-ORCAMENTO-DE-CIENCIA-E-TECNOLOGIAPODEM-INVIABILIZAR-PESQUISAS.html. Acesso em 4 abr. 2018.

ANDRADE, José Carlos Vieira de. Os Direitos Fundamentais na Constituição Portuguesa de 1976. Coimbra: Livraria Almedina, 1987.

ASENSI, Felipe Dutra. Judicialização da saúde e Conselho Nacional de Justiça: perspectivas e desafios. In: NOBRE, Milton Augusto de Brito; SILVA, Ricardo Augusto Dias da. (coord.). $\mathbf{O}$ CNJ e os desafios da efetivação do direito à saúde. 2. ed. Belo Horizonte: Fórum, 2013.

BARROSO, Luís Roberto. Da falta de efetividade a judicialização excessiva: direito à saúde, fornecimento gratuito de medicamentos e parâmetros para a atuação judicial. Revista Jurídica UNIJUS, Minas Gerais, v. 15, p. 13-38, 2008.

BONAVIDES, Paulo. Curso de Direito Constitucional. 22 ed. atual. e ampl. São Paulo: Malheiros, 2008.

BRASIL. Agência Nacional de Águas. Atlas Esgotos: página inicial. [S.I.], 2017b. Disponível em: http://atlasesgotos.ana.gov.br/. Acesso em 30 abr. 2018.

BRASIL. Câmara dos Deputados. Projeto de Lei n. 8058/2014. Institui processo especial para o controle e intervenção em políticas públicas pelo Poder Judiciário e dá outras providências. Autoria: Paulo Teixeira. Brasília, DF: Câmara dos Deputados, 2014a. Disponível em: http://www.camara.gov.br/proposicoesWeb/fichadetramitacao?idProposicao=687758 . Acesso em: 6 maio 2018. 
BRASIL. Conselho Nacional de Justiça. Relatórios de cumprimento da Resolução CNJ n. 107: Ações de saúde. Brasília, DF: CNJ, 2014b. Disponível em: http://www.cnj.jus.br/images/programas/forumdasaude/demandasnostribunais.foru mSaude.pdf. Acesso em: 29 abr. 2018.

BRASIL. [Constituição (1988)]. Constituição da República Federativa do Brasil de 1988. Brasília, DF: Presidência da República, 1988. Disponível em: http://www.planalto.gov.br/ccivil_03/Constituicao/Constituiçao.htm. Acesso em: 29 abr. 2018.

BRASIL. Ministério Público Federal. A Lava Jato em números no Paraná. Brasília, DF: MPF, 2018a. Disponível em: http://www.mpf.mp.br/grandes-casos/caso-lavajato/atuacao-na-1a-instancia/parana/resultado. Acesso em 29 mar. 2019.

BRASIL. Ministério Público Federal. A Lava Jato em números no Rio de Janeiro. Brasília, DF: MPF, 2018b. Disponível em: http://www.mpf.mp.br/para-ocidadao/caso-lava-jato/atuacao-na-1a-instancia/rio-de-janeiro/resultados. Acesso em 29 mar. 2019.

BRASIL. Presidência da República. Governo eleva orçamento de 2017 para Saúde e Educação. Brasília, DF: Planalto, 2016. Disponível em: http://www2.planalto.gov.br/acompanhe-planalto/noticias/2016/09/governo-elevaorcamento-de-2017-para-saude-e-educacao. Acesso em 4 abr. 2018.

BRASIL. Supremo Tribunal Federal. Arguição de Descumprimento de Preceito Fundamental n. 45. Rel. Min. Celso de Mello. Brasília, 29 abr. 2004.

BUCCI, Maria Paula Dallari. Buscando um Conceito de Políticas Públicas para a Concretização dos Direitos Humanos. In: BUCCI, Maria Paula Dallari et al. Direitos humanos e políticas públicas. São Paulo: Pólis, 2001. (Cadernos Pólis, 2).

BUCCI, Maria Paula Dallari. Direito Administrativo e Políticas Públicas. São Paulo: Saraiva, 2006.

CABRAL, Antonio do Passo. Pelas asas de Hermes: a intervenção do amicus curiae, um terceiro especial: Uma análise dos institutos interventivos similares - 0 amicus e o Vertreter des öffentlichen Interesses. Revista de Processo, São Paulo, n. 117, p. 9-41, set./out. 2004.

CAMBI, Eduardo; DAMASCENO, Kleber Ricardo. Amicus curiae e o processo coletivo: uma proposta democrática. Revista de Processo, São Paulo, n. 192, p. 13-45, fev. 2011.

CHIOVENDA, Giuseppe. Instituições de direito processual civil. Campinas: Bookseller, 2000. v. 1.

COSTA, Susana Henriques da. A imediata judicialização dos direitos fundamentais sociais e o mínimo existencial. Relação direito e processo. In: MENDES, Aluisio 
Gonçalves de Castro; WAMBIER, Teresa Arruda Alvim (org.). 0 processo em perspectiva. Jornadas Brasileiras de Direito Processual. São Paulo: Revista dos Tribunais, 2013. p. 345-370.

COUTINHO, Diogo Rosenthal. O Direito nas Políticas Públicas. In: MARQUES, Eduardo; FARIA, Carlos Aurélio Pimenta de (org.). A Política Pública como campo multidisciplinar. São Paulo: Unesp; Rio de Janeiro: Fiocruz, 2013.

DIDIER JUNIOR, Fredie; ZANETI JUNIOR, Hermes. Curso de direito processual civil: processo coletivo. 9. ed. rev. ampl. atual. Salvador: JusPodivm, 2014. v. 4.

GALDINO, Flávio. Introdução à teoria dos custos dos direitos: direitos não nascem em árvores. Rio de Janeiro: Lumen Juris, 2005.

GARCIA, Emerson. A corrupção. Uma visão jurídico-sociológica. Revista de Direito Administrativo, Rio de Janeiro, v. 233, p. 103-140, jul. 2003. Disponível em: http://bibliotecadigital.fgv.br/ojs/index.php/rda/article/view/45445/44994. Acesso em: 30 abr. 2018.

GRINOVER, Ada Pellegrini et al. Código brasileiro de defesa do consumidor: comentado pelos autores do anteprojeto. 9. ed. rev. atual. e ampl. Rio de Janeiro: Forense Universitária, 2007.

; WATANABE, Kazuo. $\mathbf{0}$ controle jurisdicional de políticas públicas. 2. ed. Rio de Janeiro: Forense, 2013.

HOLMES, Stephen; SUNSTEIN, Cass. The cost of rights: why liberty depends on Taxes. Nova Iorque: W.W. Norton \& Company, 1999.

LEAL, Mônia Clarissa Hennig; KOHLS, Cleize Carmelinda. Os possíveis reflexos da corrupção na análise do princípio da reserva do possível, quando da atuação do Poder Judiciário na concretização dos direitos fundamentais sociais. In: Seminário Internacional Demandas Sociais e Políticas Públicas na Sociedade Contemporânea, 11., 2014, Santa Cruz do Sul. Anais [...]. Santa Cruz do Sul: UNISC, 2014. Disponível em:

http://online.unisc.br/acadnet/anais/index.php/sidspp/article/view/11734/1513. Acesso em: 30 abr. 2018.

MANCUSO, Rodolfo de Camargo. Ação civil pública: em defesa do meio ambiente, do patrimônio cultural e dos consumidores: Lei 7.347/1985 e legislação complementar. 10. ed. rev. e atual. São Paulo: Revista dos Tribunais, 2007.

MANCUSO, Rodolfo de Camargo. O direito à tutela jurisdicional: o novo enfoque do art. 5.0, XXXV, da Constituição Federal. Revista dos Tribunais, São Paulo, n. 926, p. 135-175, dez. 2012.

MARINONI, Luiz Guilherme. Tutela de urgência e tutela da evidência. São Paulo: Revista dos Tribunais, 2017. 
MARINONI, Luiz Guilherme; ARENHART, Sérgio Cruz. Manual do processo de conhecimento. 3. ed. rev. atual. e aum. São Paulo: Revista dos Tribunais, 2004.

MAZZILLI, Hugo Nigro. A defesa dos interesses difusos em juízo: meio ambiente, consumidor, patrimônio cultural, patrimônio público e outros interesses. 22. ed. rev. ampl. e atual. São Paulo: Saraiva, 2009.

NAÇÕES UNIDAS BRASIL. Agências da ONU alertam para impactos da corrupção no desenvolvimento dos países. [S.I.]: ONU, 15 dez. 2017. Disponível em: https://nacoesunidas.org/agencias-da-onu-alertam-para-impactos-dacorrupcao-no-desenvolvimento-dos-paises/. Acesso em 4 abr. 2018.

NERY JR, Nelson; NERY, Rosa Maria de Andrade. Código de Processo Civil comentado: e legislação extravagante. 11. ed. rev. ampl. e atual. São Paulo: Revista dos Tribunais, 2010.

OLIVEIRA, Regis Fernandes de. Curso de Direito Financeiro. 6. ed. rev., atual. e ampl. São Paulo: Revista dos Tribunais, 2014.

BÔAS, Bruno Villas; SARAIVA, Alessandra. PIB brasileiro cresce 1\% em 2017 após dois anos de queda, mostra IBGE. Valor Econômico. Rio de Janeiro, 1 mar. 2018. Disponível em: http://www.valor.com.br/brasil/5354759/pib-brasileiro-cresce-1-em2017-apos-dois-anos-de-queda-mostra-ibge. Acesso em 4 abr. 2018.

RODRIGUES, Marcelo Abelha. Ação civil pública e meio ambiente. 3. ed. rev. e atual. Rio de Janeiro: Forense Universitária, 2009.

SANTOS, Boaventura de Souza. Reinventar a democracia: entre o pré-contratualismo e o pós-contratualismo. In: HELLER, Agnes et al. A crise dos paradigmas em ciências sociais e os desafios para o século XXI. Rio de Janeiro: Contraponto, 1999, p. 33-75.

SARLET, Ingo Wolfgang. Os direitos sociais como direitos fundamentais: contributo para um balanço aos vinte anos da Constituição Federal de 1988. [S.I.], 2008. Disponível em:

http://www.stf.jus.br/arquivo/cms/processoAudienciaPublicaSaude/anexo/artigo_Ing o_DF_sociais_PETROPOLIS_final_01_09_08.pdf. Acesso em: 29 abr. 2018.

SARLET, Ingo Wolfgang. A titularidade simultaneamente individual e transindividual dos direitos sociais analisada à luz do exemplo do direito à proteção e promoção da saúde. Revista Brasileira de Direito Municipal: RBDM, Belo Horizonte, ano 17, n. 60, abr./jun. 2016. Disponível em: http://www.bidforum.com.br/PDI0006.aspx?pdiCntd=240515>. Acesso em: 6 maio 2018. 
SARMENTO, Daniel. Por um Constitucionalismo Inclusivo: História Constitucional Brasileira, Teoria da Constituição e Direitos Fundamentais. Rio de Janeiro: Lumen Juris, 2010.

TRANSPARÊNCIA INTERNACIONAL BRASIL. Índice de percepção da corrupção 2018. [S.I.], 2018. Disponível em: http://ipc2018.transparenciainternacional.org.br/. Acesso em 29 mar. 2018.

ZAVASCKI, Teori Albino. Processo coletivo: tutela de direitos coletivos e tutela coletiva de direitos. 5. ed. rev. atual. e ampl. São Paulo: Revista dos Tribunais, 2011. 